\title{
Postmodern Children And THE CEMENT GARDEN OF IAN McEwan
}

RÉKA VAJDA

reejka@gmail.com

\begin{abstract}
Postmodern childhood narratives often explore disturbing themes, break social conventions and taboos. In order to comment on this kind of representation, this study will introduce Ian McEwan's controversial novel The Cement Garden (1978), the story of four children who, in the middle of a particularly hot summer, find themselves orphaned. The novel narrated by fourteen-year-old Jack explores such themes as sexuality, incest, death, the struggles of coming of age, isolation, gender roles and parent-child relationships.
\end{abstract}

Keywords: child, childhood, postmodern, Ian McEwan.

\section{Introduction}

The twentieth century or the "century of the child," as called by James and Prout $(1997,1)$, witnessed a great increase in the attention paid to childhood and children. Psychologist James Sully, the author of Studies of Childhood, wrote at the very end of the nineteenth century: "With the growth of a poetic or sentimental interest in childhood there has come a new and different kind of interest. Ours is a scientific age, and science has cast its inquisitive eye on the infant [...] we now speak of the beginning of a careful and methodical investigation of child nature." (1993, 4) He was right. By the 1970s psychologists, sociologists and anthropologists have offered extensive accounts on various aspects of childhood and the child. In 1960 French historian Philip Ariés published his controversial book Centuries of Childhood, in which he questioned some of the existing assumptions about the nature of childhood. Even though some of the book's arguments no longer stand their ground, Ariés should be credited for his "underlying assumption [...] that childhood and its subculture are always, in some sense, made and not found" (Immel and Witmore 2006, 1). What Ariés questioned is the belief that childhood is simply a biological state, that of immaturity. Instead, he put forward the suggestion that childhood is a social construct, a product of a particular cultural setting, rather than something natural. The biological immaturity of children was of course not denied, but it was pointed out that "ways in which that immaturity is understood 
is a fact of culture" (James and Prout 1997, 7). To put it another way: childhood is not universal, the view of children and childhood has changed throughout history and it is understood differently across cultures. In contemporary Western society childhood is seen as a phase very distinct from adulthood, a separate world of its own - a phase that itself is divided into categories such as early childhood or adolescence. Of course, there are generally accepted ideas about what children in a particular phase should or should not do and be like. At the same time, we still seem to be rather confused about who the child really is and what our attitude should be towards that mysterious phase called childhood.

The literary representation of children has always revolved around the same, often opposing ideas: children have been considered vulnerable, savage, innocent, imaginative, sensitive, powerless, sexual creatures, often, as in our present age, all at the same time. Today, childhood is one of the major themes in British adult fiction. What critics tend to point out is that the vast majority of these authors seem to be fascinated with the "violation of childhood through various encounters with the adult world" (Childs 2007, 124). Ian McEwan is one such writer, and the controversy surrounding him stems from the way he explores disturbing themes, such as rape, incest or murder, and breaks social conventions and taboos in his short stories and novels, which centre around child characters. His books "provoked cultural debates, moral outcries" and also earned him the nickname "Ian Macabre" (Groes 2013, 1). His "literature of shock" — as Jack Slay puts it—is especially prevalent in his early works: First Love, Last Rites (1975), In Between the Sheets (1978), The Cement Garden (1978) and The Comfort of Strangers (1981); his desire to startle the reader, however, is "evident throughout his canon" $(1996,7)$. The purpose of these and numerous other childhood narratives of the postmodern age is to reflect on social conventions, cultural norms, and to open up a discussion about rarely discussed taboos. These narratives critique our societal assumptions about childhood, which is itself a new way to represent children in literature. They highlight that what 'the child' is cannot be defined, as children and childhood are ideas constructed by our understanding of what they should be like. This study aims to discuss some of the unconventional themes found in The Cement Garden and thereby reflect on the way it responds to moral concerns and to literary conventions that idealise children.

\section{An Unconventional Narrator}

One of the most obvious signs of McEwan's unconventional approach to children can be observed in the voice of his narrator. Jack's reliability, just as well as his grey, morose, and detached voice that seemingly lacks all emotions, have received a fair 
amount of critical attention. These qualities seem to suggest that Jack, the "antithesis of the Romantic child is some kind of pathological monster." (Williams 1996, 221)

First of all, I wish to argue that the function of Jack's distinct voice is to draw attention to how this developmental stage, being on the brink of adolescence, is often lonely and isolated. David Malcolm in Understanding Ian McEwan investigates why one senses that there is "something not quite right" with regard to the narration in The Cement Garden $(2002,49)$. One of his main arguments is that Jack's emotional reserve denies sentimental sympathy and fosters the alienation of the reader. However, I believe what Jack's strange voice draws attention to is the very state he is in: he is an outsider, caught between childhood and adulthood, "between identities," as Jim Byatt puts it $(2015,72)$. The reader's sympathy for the character can very well emerge from this awareness. Jack's search for identity is illustrated, for example, in the following scene:

For a moment I perceived clearly the fact of her death, and my crying became dry and hard. But then I pictured myself as someone whose mother had just died and my crying was wet and easy again. Julie's hand was on my shoulder. As soon as I became aware of it I saw, as though through the kitchen window, the unmoving tableau we formed, sitter and stander, and I was unsure briefly which was me. [...] I wanted to go and look at myself in the mirror. (McEwan 2006, 53)

As opposed to critics who focus on Jack's alienation, Christopher Ricks associates Jack's life stage with the "shadow line." He says adolescents are special in the sense that they are perfect outsiders, constantly irritated by what is coming, by what is on the other side of the shadow line (qtd. in Hunter 2007, 131). What this idea can also explain is why Jack's voice is, in many ways, adult-like. This is illustrated, for example, in the following observations: "The people who slept on that mattress, I thought, really believed they were in the bedroom. They took it for granted that it would always be so. I thought of my own bedroom, of Julie's, my mother's, all rooms that would one day collapse." (McEwan 2006, 35)

With regards to Jack's reliability, two things need to be pointed out. Firstly, categorising him as unreliable due to his age is problematic. Young adult and child characters are also often considered unreliable due to their youth, which is associated with impaired judgment (Brugman 2014, 3). McEwan seems to be refuting this very idea by bestowing Jack with an insight that is far from innocent. Alyssa Brugman brings up the example of Huckleberry Finn, in which the narrator's innocence leads him to make overly charitable judgments about the characters in the novel. Jack, however, is not only observant but also quite right in his judgments. For instance he describes his father as "frail, irascible and obsessive" (McEwan 2006, 2), with qualities which are perfectly in line with his actions in the novel. What also needs to be highlighted is the importance of the motif of unreliable memory. Malcolm's other main argument concerns this topic: 
In the course of the text, one comes to see Jack as an unreliable narrator. His evasions are not always clearly marked, but, already indicated in the strangely detached focus of the narration, they are emphasized in one passage where Jack is confronted with another's view of events, that of his sister Sue. In her diary, which she reads to him, she records some matters that the reader knows well from Jack's account-for example, his physical appearance. She, however, also records his violence toward the others in the house, a violence of which Jack has said little. $(2002,48)$

This is how Sue records Jack's violent outburst: "Jack was in a horrible mood. He hurt Tom on the stairs for making a noise. He made a great scratch across his head and there was quite a lot of blood." (McEwan 2006, 91) However, Jack also records this event: "The day before I had made Tom cry by nicking his head with my fingernail" (2006, 84). The events are described from two different subjective perspectives: Sue's description presents it as a major incident, resulting in a 'great' scratch and a lot of blood. Jack also acknowledges it has happened; he, however, uses the word 'nick' to imply a small wound. Jack also tells of other times when he was violent: "I went to smack her hard on the back of her neck but Julie cried out, 'You dare!' so sharply that I drew back startled and my hand swept over the top of Sue's head" (2006, 110); or, "Leaning across the table I caught hold of Tom's bib and pulled him towards me. He gave out a little whimper and then a scream. [...] I had pulled Tom a good way along the table when I let go and he fell back into Julie's arms." $(2006,113)$ There is no evasion on Jack's part. What needs to be pointed out instead, is the unreliable nature of memory, a motif which recurs throughout the text. There are several instances when the children disagree about how particular events happened:

I said it was the first time it had rained since Mother died. Julie and Sue said it had rained several times since. When I asked them when exactly, they said they could not remember. Sue said she knew she had used her umbrella because it was now in her bedroom, and Julie said she remembered the sound the windscreen wipers made in Derek's car. $(2006,110)$

They also discuss that no one can remember what Sue did the day Julie first 'knew' that their mother was dying: "And you sang "Greensleeves," said Sue. 'But what did I do?' We could not remember what Sue had done, and she kept saying, 'I know I did something?’” $(2006,57)$

\section{The Wasteland and the Garden}

The setting of the novel, the isolated, Gothic house surrounded by an urban wasteland, underlines the children's peculiar relationship with life: on the one hand their lives are just beginning, and on the other, they are surrounded with death 
and destruction. The Cement Garden avoids any reference to concrete places: the location remains unnamed all through the novel, but it is argued by Malcolm that it is instantly recognisable for those who grew up in the 1960s urban Britain (2002, 55). The siblings' situation is rather a symptom of a broader social problem than an exceptional case. From Jack's description we learn that the family's house stands on a piece of empty land, as the other houses were knocked down for a motorway that had never been built. The rest of the city is filled with concrete tower blocks standing "on wide aprons of cracked asphalt where weeds were pushing through" (McEwan 2006, 24). Jack observes these buildings on more than one occasion, pointing out their uniformity and sadness and questions how a family can live inside a "rectangle of concrete" $(2006,124)$. Urban desolation is presented as general. This is further emphasised by McEwan's choice of simple, common names for the children and by the fact that the parents are only ever referred to as mother and father.

Most of this "grimly Gothic" (Bradbury, qtd. in Stierstorfer 2003, 307) novel takes place within the boundaries of the family home, a "domestic castle with thick walls, squat windows and crenellations above the front door" (McEwan 2006, 23). Gothic fiction often explores narratives of violence in the family and in latetwentieth century English Gothic tales the home is also often seen as a space "stalked by patriarchal control" (Quéma 2015, 178). The dark secret that the children guard is also a feature of the Gothic. In the cellar below the house the mother's corpse lies hidden while the odour of decomposition slowly fills the house.

The home is not only geographically isolated. Even before the death of the parents, contact with the outside world is limited, the children go to school and are allowed outside but the home itself is sealed from outsiders:

No one ever came to visit us. Neither my mother nor my father when he was alive had any real friends outside the family. They were both only children, and all my grandparents were dead. My mother had distant relatives in Ireland whom she had not seen since she was a child. Tom had a couple of friends he sometimes played with in the street, but we never let him bring them into the house. (McEwan 2006, 23)

The father's attitude mirrors that of the outside world: nature, the natural needs to be controlled. When his physical condition stops him from maintaining order in the garden, he decides to cover it in concrete:

It became apparent, probably through my mother, that the plan was to surround the house, front and back, with an even plane of concrete. My father confirmed this one evening. 'It will be tidier,' he said. 'I won't be able to keep up the garden now' (he tapped his left breast with his pipe) 'and it will keep the muck off your mother's clean floors.' He was so convinced of the sanity of his ideas that through embarrassment, rather than fear, no one spoke against the plan. (McEwan 2006, 16) 
The garden under the hands of the father becomes a mere construction, void of life. It is not possible for the children to grow up in a Rousseauian natural environment, they are prisoners in a concrete house surrounded by a concrete garden and a concrete wasteland. The fate of the garden, however, the images of weeds pushing through concrete, serve as symbols that "nature returns no matter how hard it is pitchforked out" (Childs 2012, 177). If we consider the novel a characteristically postmodern work, this failed attempt to impose order on chaos can be seen as a criticism of modernism, which is seen to have a highly controlled attitude to reality by some scholars, such as Linda Hutcheon or Ihab Hassan. In this sense what we are presented with here is how in postmodernism chaos can no longer be contained. Here, the fathers and mothers are dead and chaos reigns.

\section{Homes and Boys}

The Cement Garden is ultimately about "the absent parents" as McEwan stated in an interview (Deveney 2005). Of course, much of the novel focuses on the orphaned children; the parents, however, have been largely 'absent' even before their death. They fail to provide a proper nurturing environment and they are unable to transmit healthy values and attitudes or serve as role models for their children. Child characters left alone with the responsibility of building their own identities without parental guidance "often end up fearful or damaged" in childhood narratives of the 1970s (Sands-O'Connor 2012, 227). Jack is left alone in his wrestling with the problem of identity versus social norms. All through the novel there are references to his concern with masculinity. "I stood up and held the comic out of sight. I wished I had been reading the racing page of my father's paper, or the football results. [...] I hooked my thumbs into my pockets, moved my weight on to one foot and narrowed my eyes a little." (McEwan 2006, 9) His masculine behaviour mirrors that of the father's: he is very insecure, yet he desires to be perceived as tough. This is emphasised in the scene when he is looking at himself in the mirror: "I stared at my own image till it began to dissociate itself and paralyse me with its look. It receded and returned to me with each beat of my pulse, and a dark halo throbbed above its head and shoulders. "Tough,' it said to me. 'Tough.' And then louder, 'Shit... piss... arse.." (McEwan 2006, 21) Jack's constant rereading of the science fiction book Sue had given him and his fantasies about Commander Hunt reveal his desire for a role model. Commander Hunt is the opposite of Jack's father: a fearless leader and at the same time quite a domestic-minded person. Jack's desire to become like him is evident in such scenes as when he is confronted with Julie's boyfriend, Derek, a rich snooker-player with "broad shoulders" and at a "perfect age of twenty-three": jealousy and the feeling of 
inferiority drive Jack to run "upstairs with the book to the bedroom" and to slam "the door hard” (McEwan 2006, 94).

Jack feels the need to conform to expected gender roles but he also sees how superficial clothes are, as far as identity is concerned. In the scene when Tom dresses up as a girl for the first time, Jack's views are confronted by those of Julie. Julie claims that for Jack it is humiliating to look like a girl because he thinks it is humiliating to be a girl. Jack is unable to defend his opinion, his answer signals that the view is not his own, it was passed on to him, it is the societal view:

Girls can wear jeans and cut their hair short and wear shirts and boots because it's okay to be a boy, for girls it's like promotion. But for a boy to look like a girl is degrading, according to you, because secretly you believe that being a girl is degrading. Why else would you think it's humiliating for Tom to wear a frock?' 'Because it is,' I said determinedly. (McEwan 2006, 47)

Jack's view is contrasted with that of Tom's friends from his own age group, who are not yet bothered by such social norms: "Quite often now Tom played in the street in Sue's skirt. None of the other children teased him like I thought they would. They did not even seem to notice." (McEwan 2006, 86) Jack himself is both excited and scared upon seeing a cross-dressed Tom: "How easy it was to be someone else. I crossed my arms and hugged myself. They are only clothes and a wig, I thought, it is Tom dressed up. But I was looking at another person, someone who could expect a life quite different from Tom's." (McEwan 2006, 77)

\section{Matters of Sexuality}

The Cement Garden, on the one hand, highlights the importance of proper sexual education and, on the other, calls attention to the dangers of misinformation and the repression of healthy sexual curiosity in children. Laurenz Volkmann argues that sexuality in The Cement Garden is extremely disturbing, which is often the claim made against the novel:

Sexuality and violence are incorporated in the novel in a uniquely shocking and appalling way. This is done in a seemingly unemotional rendering of how social taboos are broken, which on the one hand transgresses earlier modes of dealing with the topic; on the other hand, simultaneously by means of the novel's becoming a cult novel due to its graphic and seemingly tasteless descriptions of sex and violence, it turns these transgressions into 'marketable' assets. $(2003,308)$

Of course, there are numerous contradictory discourses with regards to the sexuality of children (Robinson 2013, 6). They can be considered asexual, innocent and vulnerable to adult exploitation. Some view children's sexuality as dangerous to 
society and to the moral development of the child, while others consider it normal and critical for the development of a vibrant society (Robinson 2013, 6). While during the twentieth century, the earlier denial of children's sexuality continued, a new discourse was introduced primarily through the works of Sigmund Freud, who challenged the ideas of childhood innocence and argued that children are sexual beings and they need to express their sexuality (Robinson 2013, 49). In the progressive era, children's sex-play was seen as healthy and its repression was thought to be one of the reasons behind neurosis in adulthood. So, parents were encouraged to accommodate their children's erotic impulses and curiosities, as they were perceived to be ways that children learned about the world (Robinson 2013, 90). By the 1980s another re-evaluation of childhood sexuality had started and once again it came to be considered something dangerous to children:

The re-evaluation was largely a result of the recognition of child sexual abuse as a widespread social phenomenon, and its reconceptualization from a practice in which the victims were often blamed for the behaviour. [...] In this context, children's vulnerability is linked to their lack of knowledge of sexual behaviours and to their limited access to power. (Robinson 2013, 50)

Most readers are shocked by McEwan's explicitness "by which they usually mean his description of sexual games: the narrator 'knowingly, knowing nothing' plays with his two sisters" (Walkowitz 2008, 507). Volkmann's phrase, "seemingly tasteless descriptions of sex," highlights how a taboo topic, such as sexual experimentation between children, ends up being labelled as tasteless, regardless of the mode of description. As it can be seen in the following excerpt, Jack's descriptions, explicit as they may be, are not tasteless or vulgar: "Sue was rather thin. Her skin clung tightly to her rib cage and the hard muscular ridge of her buttocks strangely resembled her shoulder blades. Faint gingerish down grew between her legs." (McEwan 2006, 11) The naked body is something strange and curious for the children, as it is highlighted in the game itself: they are scientists and aliens. Such games are widely recognised methods by which children try to understand the world and satisfy their curiosity (Goldman and Goldman 1988, 148). An important point brought up by Ronald and Juliette Goldman is that these games are very common because of all the sexual secrecy practiced by the adult world $(1988,148)$. This is emphasised in the novel through Jack's assumption that the reason why Sue put an end to their games is that she had learned something at school and was ashamed of herself. The other issue is highlighted in connection with Jack's masturbation. In this case the mother chooses to talk about it, but instead of accommodating Jack's "erotic impulses and curiosities," as parents were encouraged to do in the era (Robinson 2013, 90), she associates the negative aspects of Jack's coming of age with his giving in to the urge to masturbate: 
"Yes, look at yourself,' she said in a softer voice. 'You can't get up in the mornings, you're tired all day, you're moody, you don't wash yourself or change your clothes, you're rude to your sisters and to me. And we both know why that is. Every time...' She trailed away, and rather than look at me stared down at her hands in her lap. 'Every time... you do that, it takes two pints of blood to replace it." (McEwan 2006, 29)

Jack's response is rebellion: "I abandoned all the rituals of personal hygiene. I no longer washed my face or hair or cut my nails or took baths. I gave up brushing my teeth. In her quiet way my mother reproved me continuously, but I now felt proudly beyond her control." (McEwan 2006, 21) This parental attitude is what Michel Foucault also refers to in the 1975 interview 'Body and Power.' He calls attention to the fact that this view on masturbation is a social construct as the restriction on it hardly started until the eighteenth century, when suddenly people started to be appalled by the fact that children masturbate. Sexuality became an object of concern, analysis and control; as a result, the body became "the issue of conflict between parents and children, the child and the instances of control" $(1975,55)$.

Committing incest can be seen as a cure for the children's isolation, it is an attempt to keep the family together. As McEwan puts it "the oedipal incestuous forces - are also paradoxically the very forces which keep the family together" (qtd. in Hamilton 2010,19). None of what happens is seen as abnormal or immoral by the children, rather as something completely natural. Childs compares the novel with The Lord of the Flies and says what we are reminded of is how the adult world "provides checks not on the children's natural aggression but on their natural sexuality" (2012, 175). Byatt writes:

Reading sibling incest between minors is infused, beyond the instinctual resistance to incest, with the multiple dangers and stigmas associated with paedophilia, voyeurism, the sexually active minor and the private bodily exploration that takes place in the adolescent bedroom. On top of this, the failure in culture to distinguish fully between incest and rape creates an unease that is only alleviated by the exposition of the act in its non-abusive form, which is nonetheless subject to the same basic prohibitions as any other portrayal of alternative modes of sexuality. $(2015,65)$

The growing fear of sexual abuse starting in the 1980s also resulted in the demonization of anything that can, in any way, be connected to paedophilia. The naturalisation of sexuality, which is derived from cultural assumptions about the asexuality of children both in mind and body, has achieved a moral ascendancy. Children and even adolescents are seen as innocent but susceptible to inappropriate sexuality. The problem with this is that anyone who "challenges the taken-forgrantedness" or "questions the validity" of these ideas, risks being seen as an apologist for the sexual abuse of children (Hawkes and Egan 2008, 194). Georges Bataille 
in Erotism writes about how nakedness can be contrasted with self-possession: "It is a state of communication revealing a quest for a possible continuance of being beyond the confines of the self" $(1962,17)$. While previously there has been an emphasis on the external, on the voyeuristic gaze of Jack, the focus shifts to the internal in the last scene of the novel. The emphasis is not on the sexual act itself but on closeness and unity, as opposed to the feelings of loneliness, isolation and exclusion that permeate the rest of the novel: "I took her hand and measured it against mine. It was exactly the same size. We sat up and compared the lines on our palms, and these were entirely different. We began a long investigation of each other's body." (McEwan 2006, 136)

\section{Conclusion}

Ian McEwan and many other writers since, have tried to construct an unsentimental version of childhood, raising questions about the innocence and morality of children. The absence of moral concern is one of the main charges that has been levelled against The Cement Garden, while in fact, as it has been pointed out in this study, it discusses a number of serious issues, such as parental absence, physical and social isolation, the suppression of natural development or the harmful effects of certain ideas about childhood. McEwan's uniqueness lies in that he constantly underscores his own uncertainty in treating these questions (Head 2013, 46), which points at how, at least from a postmodern perspective, there are no absolutes, no certainties, no universal understanding. Childhood, in fact, the whole world is socially constructed by us, humans (Dahlberg, Moss and Pence 1999, 23).

\section{Works Cited}

Bataille, Georges. 1962. Erotism: Death and Sensuality. San Francisco: City Lights Books.

Brugman, Alyssa. 2014. "Qualities of Friendship: Unreliable Narration in Young Adult Fiction." PhD diss., University of Canberra.

Byatt, Jim. 2015. Rethinking the Monstrous: Transgression, Vulnerability and Difference in British Fiction Since 1967. Lanham: Lexington Books.

Childs, Peter. 2007. "Fascinating Violation." In British Fiction of the 1990s, edited by Nick Bentley, 123-134. Routledge.

Macmillan. 
Dahlberg, Gunilla, Peter Moss and Alan R. Pence. 1999. Beyond Quality in Early Childhood Education and Care: Postmodern Perspectives. London: RoutledgeFalmer.

Deveney, Catherine. 2005. "First Love, Last Writes." Scotsman on Sunday. http:// www.ianmcewan.com/resources/interviews.html.

Foucault, Michel. 1975. "Body/Power." In Power/Knowledge: Selected Interviews and Other Writings 1972-1977, translated and edited by Colin Gordon et al., 55-62. New York: Pantheon.

Goldman, Ronald and Juliette Goldman. 1988. Show Me Yours: Understanding Children's Sexuality. Ringwoord, Vic: Penguin Books.

Groes, Sebastian. 2013. "A Cartography of the Contemporary: Mapping Newness in the Work of Ian McEwan" In Ian McEwan: Contemporary Critical Perspectives, edited by Sebastian Groes, 1-13. London: Continuum.

Hamilton, Ian. 2010. "Points of Departure." In Conversations with Ian McEwan, edited by Ryan Roberts, 3-19. University Press of Mississippi.

Hawkes, Gail and Danielle Egan R. 2008. "Landscapes of Erotophobia: The Sexual(ized) Child in the Postmodern Anglophone West." Sexuality \& Culture 12: 193-203. SpringerLink. https://doi.org/10.1007/s12119-008-9038-6

Head, Dominic. 2013. Ian McEwan. Manchester University Press. https://doi.org/10.7765/9781847791733

Hunter, Adrian. 2007. The Cambridge Introduction to the Short Story in English. Cambridge University Press. https://doi.org/10.1017/CBO9780511611360

Immel, Andrea and Michael Witmore. 2006. "Introduction" In Childhood and Children's Books in Early Modern Europe, 1550-1800, edited by Andrea Immel and Michael Witmore, 1-19. New York: Routledge.

James, Allison and Allen Prout. 1997. "Introduction" In Constructing and Reconstructing Childhood: Contemporary Issues in the Sociological Study of Childhood, edited by Allison James and Allen Prout, 1-7. London: Falmer Press.

Malcolm, David. 2002. Understanding Ian McEwan. University of South Carolina Press.

McEwan, Ian. 2006. The Cement Garden. London: Vintage Books.

Quéma, Anne. 2015. Power and Legitimacy: Law, Culture and Literature. University of Toronto Press. https://doi.org/10.3138/9781442619289

Robinson, Kerry. H. 2013. Innocence, Knowledge and the Construction of Childhood: The Contradictory Nature of Sexuality and Censorship in Children's Contemporary Lives. London and New York: Routledge.

Sands-O'Connor, Karen. 2012. "Shackled by Past and Parents: The Child in British Children's Literature after 1970." In The Child in British Literature, edited by Adrienne E. Gavin, 225-37. New York: Palgrave Macmillan. 
https://doi.org/10.1057/9780230361867_15

Slay, Jack. 1996. Ian McEwan. New York: Twayne Publishers

Stierstorfer, Klaus. 2003. Beyond Postmodernism: Reassessment in Literature, Theory and Culture. Berlin: Walter de Gruyter. https://doi.org/10.1515/9783110906813

Sully, James. 1993. Studies of Childhood. Psychology Press.

Volkmann, Laurenz. 2003. "Extension of the Battle Zone: Ian McEwan's Cult Novel The Cement Garden." In Beyond Postmodernism: Reassessment in Literature, Theory and Culture, edited by Klaus Stierstorfer, 303-18. Berlin: Walter de Gruyter.

Walkowitz, Rebecca. L. 2008. "Ian McEwan." In A Companion to the British and Irish Novel 1945-2000, edited by Brian W. Shaffer, 504-14. Malden, MA:John Wiley \& Sons. https://doi.org/10.1002/9780470757611.ch38

Williams, Christopher. 1996. "Ian McEwan's The Cement Garden and the Tradition of the Child/Adolescent as 'I-Narrator.'” Atti del XVI Convegno Nazionale dell'AIA: Ostuni (Brindisi) 14-16 ottobre 1993, 211-23. Fasano di Puglia: Schena. 